\title{
STUDI PRESTASI TAEKWONDO PADA NOMOR KYORUGI DAN PADA NOMOR POOMSE DI KOTA BENGKULU
}

\author{
Rizky Govinda Eka Saputra ${ }^{1}$, Dian Pujianto ${ }^{2}$, Yarmani $^{3}$ \\ ${ }^{123}$ Prodi Penjas, FKIP, Universitas Bengkulu, Kota Bengkulu, Indonesia
}

\begin{tabular}{l}
\hline Info Artikel \\
\hline Sejarah Artikel: \\
Diterima April 2020 \\
Direvisi April 2020 \\
Diterima April 2020 \\
Tersedia online April 2020 \\
\hline \\
Kata kunci: \\
Studi Prestasi, Atlit, Olaharaga \\
Taekwondo \\
\hline
\end{tabular}

\begin{abstract}
Abstrak
Penelitian ini bertujuan mengetahui Studi Prestasi Atlit Taekwondo Pada Nomor kyorugi Dan Pada Poomse Di Kota Bengkulu. Jenis penelitian ini adalah deskriptif kualitatif. Subjek pada penelitian ini terdiri dari Atlit, Pengurus club (Pembina), pelatih dengan Jumlah 36 orang. Teknik pengumpulan data yang digunakan adalah dengan survei (kuesioner) dan dokumentasi. Instrument yang digunakan adalah angket. Teknik analisis data yang digunakan adalah persentase. Hasil kueosioner Atlit, pengurus club (Pembina), Dengan Jumlah 36 orang, maka diperoleh hasil angket dengan presentase atlit $82,7 \%$ dalam kategori sangat baik. Pelatih memperoleh presentase $89,9 \%$ dalam kategori sangat baik dan pengurus memperoleh hasil dengan presentase 90,2\% dengan kategori sangat baik. Sehingga dapat disimpulkan bahwa Studi Prestasi Atlit Pada Nomor Kyorugi Dan Pada Nomor Poomse Di kota Bengkulu memiliki kategori sangat baik dengan rata-rata skor $157,8(87,62 \%)$.
\end{abstract}

\section{Abstract}

This Study aims to determine The Achievement Of Taekowondo On Kyorugi Numbers And On Poomse Numbers In Bengkulu City. This type research is descriptive qualitative. Subjects in this study were athletes, club administrators (coach), coaches with total 36 people. Data collection teghnigues used were surveys (questionnaires), and documentation. The instrument used was a closed questionnaire, the data analysis technique used is percentage. The result of this study were taken from the athelet questionnaire, club managers (coaches) with a total of 36 people, then the questionnaire result were obtained with a percentage of $82,7 \%$ of the criteria of strongly disagree, $89,9 \%$ of the trainers in the sufficient category, and the management obtained result wit percentage $90,2 \%$. With enough kategory, so it can be conclude that Achievement Study Of Taekwondo Atheles In Kyorugi Numbers And Poomse Number In Bengkulu City has sufficient categories with an average score of 157,8 (87,62\%). 


\section{PENDAHULUAN}

Taekwondo merupakan salah satu cabang olahraga beladiri yang berkembang di dunia yang berasal dari Korea Selatan. Pada tahun 1972, Kukkiwon didirikan, sebagai markas besar Taekwondo, Kejuaraan dunia Taekwondo yang pertama diadakan pada tahun 1973 di Kuk Ki Won, Seoul, Korea Selatan, sampai saat ini kejuaraan dunia rutin dilaksanakan setiap 2 tahun sekali.

Taekwondo mulai berkembang di Indonesia pada tahun 70-an, yang pada saat itu masih mempunyai 2 aliran yang berbeda, yaitu aliran ITF (International Taekwondo Federation) dan WTF (World Taekwondo Federation). Akhirnya pada tahun 1981 diadakannya musyawarah nasional diantara kedua organisasi tersebut, yang berhasil membentuk organisasi baru yaitu Taekwondo Indonesia yang berafiliasi ke WTF, yang secara struktural organisasi nasional adalah Pengurus Besar Taekwondo Indonesia (PBTI) yang berpusat di Jakarta. Taekwondo yang semakin maju dan populer muladipertandingkan diberbagai pertandingan di Indonesia secara Rutin,seperti diadakannya pertandingan baik itu ditingkat kota, daerah, provinsi, nasional, bahkan internasional. Pertandingannya pun banyak menarik perhatian masyarakat dari berbagai kalangan. Pembinaan dan perkembangan di bidang olahraga harus dikembangkan sedini mungkin.
Untuk menciptakan generasi-generasi muda yang mandiri, sportif, dan berprestasi serta berpotensi untuk mengharumkan nama bangsa. Salah satu cabang olahraga yang telah mengharumkan nama bangsa di mata dunia adalah cabang olahraga beladiri yaitu Taekwondo.Dalam mencapai prestasi olahraga ada empat faktor yang perlu diperhatikan. Menurut (Syafruddin 1999: 24) keempat faktor tersebut adalah faktor kondisi fisik, teknik, taktik, dan mental. Bila salah satu unsur belum dikuasai, maka betapa baiknya ketiga unsur yang lain harus dikuasai, pembinan dengan pengembangan olahraga sudah selayaknya kita memberikan perhatian khusus sehingga dari prestasi diharapkan untuk perlu dikaji ulang dengan melakukan penelitian dibidang olahraga khususnya Taekwondo.

Taekwondo adalah seni beladiri yang menggunakan banyak teknik,baik pukulan, tangkisan, dan tendangan.Dari bebagai teknik yang diajarkan dalam beladiri Taekwondo teknik tendangan adalah teknik yang paling dominan dalam beladiri Taekwondo ini sehingga harus benarbenar dimantapkan dan di maksimalkan. Tendangan adalah teknik yang sangat dominan dalam olahraga Taekwondo ini. Seperti yang diungkapkan Suryadi (2002: 32) bahwa : " teknik tendangan sangat dominan dalam seni beladiri Taekwondo, bahkan harus diakui bahwa Taekwondo sangat dikenal karena kelebihannya dalam teknik 
tendangan Di dalam olahraga Taekwondo ada dua jenis cabang yang diperlombakan yaitu kiyouruki (bertarung) dan poomsae (gerakan jurus).Salah satu tendangan yang paling sering digunakan pada saat pertandingan kiyouruki adalah tendangan dollyo chagi. Menurut Suryadi (2002: 45) tendangan dollyo chagi adalah pada dasarnya tendangan ini menggunakan bantalan telapak kaki (ap chuk), namun sering pula menggunakan baldeung (punggung kaki), terutama jika digunakan di dalam pertandingan. Dalam pertandingan Olahraga Taekwondo untuk memperoleh poin harus menggunakan teknik serangan yang benar, bertenaga, serta faktor yang paling penting adalah kecepatan menendang dalam menyerang maupun bertahan.

\section{METODE}

Berdasarkan permasalahan yang dibahas dalam penelitian ini, maka penelitian ini bersifat deskriptif, bertujuan untuk meneliti prestasi atlit Taekwondo pada nomor kyorugi dan nomor poomse. Persiapan-persiapan yang dilakukan adalah menetukan subjek dan objek, subjek, pembuatan angket, pengumpulan data dengan cara memberikan angket yang telah disusun terhadap subjek.

Berdasarkan permasalahan yang dibahas dalam penelitian ini, maka penelitian ini bersifat deskriptif, bertujuan untuk meneliti prestasi atlit taekwondo pada cabang nomor kyorugi dan cabang nomor poomse. Persiapan-persiapan yang dilakukan adalah menetukan subjek dan objek, subjek, pembuatan angket, pengumpulan data dengan cara memberikan angket yang telah disusun terhadap subjek.

Metode deskriptif kualitatif yaitu memaparkan data yang ada sesuai dengan keadaan yang sebenarnya. Metode deskriptif dapat di artikan sebagai prosedur pemecahan masalah yang diselidiki dengan menggambarkan atau melukiskan keadaan subjek atau objek penelitian berdasarkan faktorfaktor yang tampak atau sebagaimana adanya.

\section{Subjek penelitian}

Apa yang dimaksud dengan subjek, adalah Atlit tempat atau benda yang diamati dalam rangka pembuatan sebagai sasaran ( kamus bahasa Indonesia, 1989:862 ), Adapun subjek penelitian dalam tulisan ini adalah 36 pelaku olahraga Taekwondo di Kota Bengkulu. Terdiri dari 30 orang yamg diambil dari dojang synergy, dojang teratai dan dojang mandiri, masing masing dojang diambil 5 orang yang berumur minimal 15 tahun, ditambah 1 orang pelatih dan 1 orang Pembina dari setiap dojang di Kota Bengkulu.

\section{Objek}

Yang dimaksud objek penelitian, adalah hal yang menjadi sasaran penelitian ( kamus bahasa Indonesia 1989 ) menurut ( Supanto, 2000:21 ) objek penelitian adalah himpunan elemen yang dapat berupa orang oragnisasi atau barang yang akan diteliti objek penelitian ini ialah "studi prestasi atlit Taekwondo pada nomor kyourugi dan nomor poomse di kota Bengkulu". Data primer dikumpulkan 
melalui angket yang berpedoman pada daftar pertanyaan yang telah dipersiapakan. Pengambilan data sekunder melalui pencatatan dengan pelatih/sabem dan atlit yang terkait serta berpedoman pada daftar pertanyaan yang telah dipersiapkan

Instrumen disusun
dengan langkah-langkah
sebagai
berikut: 1) membuat
berdasarkan variabel, 2) menyusun
butir-butir pertanyaan sesuai dengan
inidikator variabel, 3) menyusun
angket dan aspek yang diukur. Keabsahan data untuk memvalidasi angket yaitu dengan menggunakan validitas rasional, validitas rasional adalah validitas yang diperoleh atas dasar pemikiran, validitas yang di peroleh dengan berpikir secara logis (Sudijono 2009). Dalam penelitian ini validasi secara logis dilakukan oleh ahli yakni ; dosen pendidikan jasmani Drs Tono Sugihartono, M.pd, pengurus Dojang/club Firman, Dani dan Yulizar S.pd. pendestribusian angket diberikan terhadap responden yang berjumlah 36 orang. Peneliti mengelola data hasil angket dengan menggunakan presentase, menurut Anas Sujiono (2012:43), dengan rumusan sebagai berikut : Hasil Studi Prestasi Atlit Taekowndo Pada Nomor Kyorugi Dan Pada Nomor Poomse di Kota Bengkulu kriteria skor ditentukan dengan menggunakan Penilaian Acuan Norma (PAN) dalam skala. Dalam peneliti menggunakan teknis analisis dan model miles dam huberman. Analisis data dalam penelitian kualitatif ini dilakukan pada saat pengumpulan data dan berlangsung, dan setelah selesai pengumpulan data dalam periode tertentu. Pada saat wawancara, peneliti sudah melakukan analisis data dalam jawaban yang di wawacarai. Miles dan Huberman mengemukakan bahwa aktivitas dalam analisis data kualitatif dilakukan secara interaktif. Aktivitas dalam analisis data yaitu data reduction, data display, dan conlusion drawing/verifications. ( sugiyono 2010:337 )

\section{Data reduction}

data yang diperoleh dari lapangan jumlahnya cukup banyak. Untuk itu perlu dicatat secara teliti dan rinci. Seperti telah ditemukan, makin lama peneliti dilapangan, maka jumlah data akan makin banyak, kompleks dan rumit. Untuk itu diperlukan segera dilakukan analisis data melalui reduksi data. Mereduksi data berarti merangkum, memilih hal-hal yang pokok, memfokuskan pada halhal yang penting, tema dan polanya dan membuang yang tidak perlu. Dengan demikian data yang telah direduksi akan memberikan gambaran yang jelas, dan mempermudah peneliti untuk melakukan pengumpulan data selanjutnya, dan mencarinya dia diperlakukan. Reduksi data dalam penelitian ini, menggunakan computer/pc, dengan memberikan kode pada aspek-aspek dalam data penelitian analisis semiotika pada dojang Taekwondo di kota bengkulu dan temuan dilapangan bahwa analisis pada dojang Taekwondo dilihat dari tiga faktor utama yang mempengaruhi yaitu, maka pelatih, atlit, dan prestasi atlit, hasil wawancara dengan para informan. Penelitian melakukan pemusatan permasalahan dan membuang data 
yang tidak relevan dengan penelitian ini.

\section{Data display ( penyajian data )}

Setelah data reduksi, maka langkah selanjutnya adalah mendisplaykan data. Penyajian data melibatkan langkah-langkah yang mengorganisaikan data, yakni menjalin data yang satu dengan data yang lain, sehingga seluruh data yang dianalisis benar-benar dilibatkan dalam satu kesatuan. Setelah memilih data yang relevan dan mereduksi data yang tidak sesuai dengan penelitian ini, penulis melakukan penyajian data, berupa cuplikan hasil wawancara dan beberapa hasil observasi dan beberapa sumber tertulis. Agar mudah dipahami dan tidak keluar dari koridor penelitian, penulis mengabungkan data yang sudah direduksikan tersebut dengan narasi dari penulis. Setelah penyajian data yang dikaloborasikan dengan narasi penulis, selanjutnya dilakukan analisis dengan teori-teori yang relevan. Pada penelitian ini, penulis menggunakan teori-teori yang variatif sehingga menghasilkan analisis yang tajam dan dapat dipercaya akhirnya, proses analisia yang melibatkan teori dengan data penelitian ( hasil wawancara ) tersebut mampu memghasilkan kesimpulan penelitian.

3. Conclusion drawing/verification(penarikan
kesimpulan dan verifikasi ) Penelitian pada dasarnya mengimplemetasikan prinsip induktif dengan mempertimbangkan pola-pola data yang ada dan atau kecenderungan dari display data yang telah dibuat. Ada kalanya kesimpulan telah tergambar sejak awal, namun kesimpulan final tidak dapat dirumuskan secara memadai, tanpa peneliti menyelesaikan analisis seluruh data yang ada. ( Sugiyono, 2010:345 )

Peneliti mulai mampu memprediksi kesimpulan yang dapat ditarik dari penyajian data yang telah dibuat. Meskipun demikian, berdasarkan pendapat sugiyono di atas, kemantapan kesimpulan hanya dapat setelah seluruh proses penelitian selesai dilakukan. Untuk itu, penyajian kesimpulan dan saran, penulis lakukan stelah semua proses penelitian selesai, dari kesimpulan tersebut, didapatlah saran-saran yang dikiranya mampu memberikan konstribusi positif bagi clothing brand Philip works ( Sugiyono, 2010:341345 ).

\section{HASIL}

Berdasarkan hasil analisis data penelitian yang ada di atas maka dapat dilihat bahwa studi perstasi atlit taekwondo pada nomor kyorugi dan nomor poomse di Kota Bengkulu, dengan soal pernyataan program latihan pada nomor kyorugi dan poomse skor 147 ( $81,6 \%)$ dan pernyataan program seleksi pada nomor kyorugi dan nomor poomse skor 165 (91,6\%), studi prestasi atlit taekwondo pada nomor kyorugi dan pada nomor poomse di Kota Bengkulu pernyataan tentang program latihan yang belum terpusat dengan skor 159 ( $88,3 \%)$ dan pernyataan tentang kesinambungan atlit terhadap program latihan mempunyai skor $165(91,6 \%)$ sedang analisis tentang kontribusi pengurus terhadap dojang mempunyai skor $157(87,2 \%)$ dan sedangnkan 
pernyataan dana yang disiapkan untuk kejuaraan dengan skor 168 (93,3\%). Sehingga dapat disimpulkan bahwa studi prestasi atlit taekwondo pada nomor kyorugi dan pada nomor poomse di Kota Bengkulu memiliki kriteria yang sangat baik dengan ratarata skor $157,8(87,6 \%)$.

Berdasarkan data yang telah di isi responden dari 2 item pernyataan yang terdiri dari indikator kepengurusan memiliki kriteria sangat baik dengan penyataan kontribusi Pembina terhadap dojang memiliki mean 4,3 (87,2\%), indikator pengurus dengan pernnyataan dana yang disiapkan untuk kejuaran memiliki kriteria sangat baik dengan mean 4,6 $(93,3 \%)$, Sehingga dapat disimpulkan bahwa studi prestasi atlit taekwondo pada nomor kyorugi dan nomor poomse di Kota Bengkulu Hasil analisis dari 2 indikator memiliki kriteria sangat baik dengan mean 4,45 $(90,2 \%)$ data penelitian juga dapat dilihat dalam bentuk histogram seperti gambar di bawah.

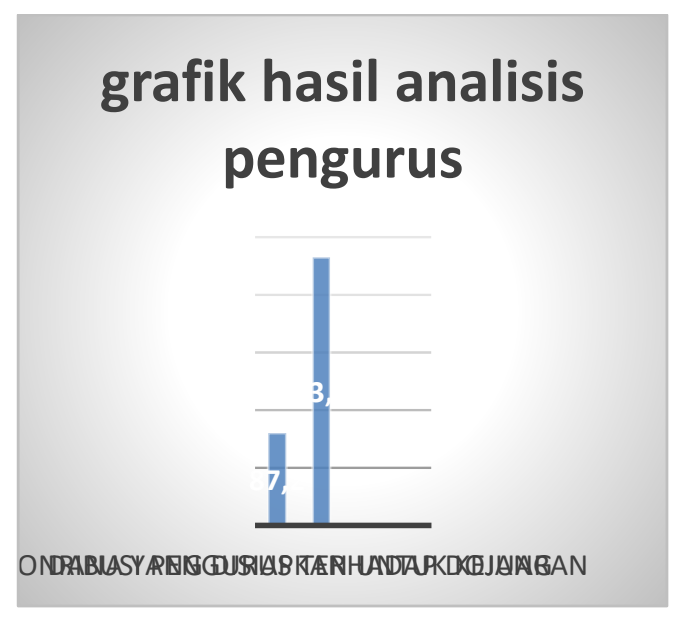

Gambar 1. Grafik Batang hasil analisis data pengurus
Berdasarkan data yang telah di isi responden dari 2 item pernyataan yaitu program seleksi atlit memiliki kriteria sangat baik dengan mean 4,0 $(81,6 \%)$, dan sedangkan pernyataan program latihan untuk atlit memiliki kriteria sangat baik dengan mean 4,1 $(83,8 \%)$, Sehingga dapat disimpulkan bahwa studi perstasi atlit taekwondo pada nomor kyorugi dan pada nomor poomse di kota bengkulu yang memiliki kriteria sangat baik dengan rata-rata mean 4,05 (82,7\%). Hasil analisis data penelitian juga dapat dilihat dalam bentuk histogram seperti gambar di bawah.

Berdasarkan data yang telah di isi responden dari 2 item pernyataan program latihan yang belum terpusat yang memiliki kriteria dengan mean $4,5 \quad(91,6 \%)$, dan pernyataan kesinambungan atlit terhadap program memiliki presentase dengan mean 4,5 $(88,3 \%)$ Sehingga dapat disimpulkan bahwa studi perstasi atlit taekwondo pada nomor kyorugi dan pada nomor poomse di kota bengkulu pelatih memiliki kriteria sangat baik dengan 2 item pernyataan program latihan yang belum terpusat dan kesinambungan terhadap program latihan yang memiliki kriteria sangat baik dengan rata-rata mean 4,45 (89,95\%). Berdasarkan hasil penelitian yang diperoleh bahwa pembahasan mengenai studi prestasi atlit Taekwondo pada nomor kyorugi dan pada nomor poomse di Kota Bengkulu

Berdasarkan hasil kuesioner yang diberikan kepada atlit, Pengurus klub, pelatih di Kota Bengkulu yang terdiri dari atlit, pengurus dan pelatih Sehingga dapat disimpulkan bahwa Studi Prestasi Atlit Taekwondo Pada 
Nomor Kyorugi Dan Pada Nomor Poomse di Kota Bengkulu memiliki kriteria yang cukup dengan rata-rata skor 157,8 (87,62\%) Persepsi Studi Prestasi Atlit Taekowndo Pada Nomor Kyorugi Dan Pada Nomor Poomse di Kota Bengkulu dari faktor pelatih, atlit dan pengurus termasuk kriteria sangat baik. Hal ini dapat dilihat dari 6 pernyata yang dibuat yaitu sebagai berikut: 1). Pengurus dan pihak terkait harus mempersiapkan dana dalm setiap kejuaraan. 2). Pengurus harus memiliki kontribusi terhadap dojang. 3). Program latihan pada atlit kyorugi sangat sulit. 4). Program latihan pada atlit poomse. 5). Pelatih harus memiliki program latihan jangka panjang untuk atlit 6). Pelatih melaksanakan ajang seleksi untuk atlit yang ingin mengikuti kejuaran.

Setelah melakukan penelitan langsung kelapangan hasil yang ditunjukan dari prestasi Atlit Taekowndo Di Kota Bengkulu menunjukan bahwa pada nomor Kyorugi lebih dominan memberikan prestasi dibandingkan pada nomor Poomse dikarena kan dari ajang seleksi hingga kejuaraan lebih banyak pada nomor Kyorugi sedang pada nomor Poomse lebih sedikit dikarena kan belum banyak pelatih khusus Poomse dan sulit menemukan bibit-bibit Atlit yang sesuai dengan kriteria pada nomor Poomse Atlit atau Olahragawan adalah orang yang mengikuti pelatihan secara teratur dan Kejuaraan dengan penuh dedikasi untuk mencapai prestasi pasal 1 ayat 7 UUD 2005 tentang keolahragaan didalam penelitian ini indikator atlit mendapat kategori sangat baik dengan presentase $(81,6 \%)$ dan $(83,8 \%)$ dari 2 item pernyataan hal ini menujukan bahwa atlit dalam perkembangan olahraga Taekwondo di Kota Bengkulu memiliki perkembangan yang baik berdasarkan hasil analisis data kuesioner. Hal ini adalah salah satu hal yang baik karena atlit adalah sosok sentral bagai olahraga itu sendiri, dari hasil observasi lapangan ditemukan bahwa atlit Taekwondo memiliki prestasi hal itu dibuktikan dengan berhasil menjuarai beberapa kejuaran nasional dikelas senior seperti di kejuaran prapon papua beberapa waktu lalu, hal ini menjadikan luar biasa dikarnakan dari 3 club yang menjadi responden belum memiliki pelatih/sabem yang berpengalaman, atlit hanya dilatih oleh pelatih/sabem dalam olahraga Taekwondo di Kota Bengkulu .

\section{SIMPULAN}

Nomor Poomse kurang
memberikan prestasi yang di
harapkan dengan hasil tersebut nomor Poomse masuk dalam kategori Baik. Hasil kuesioner Studi Prestasi Atlit Taekwondo Pada Nomor Kyorugi Dan Pada Nomor Poomse Di Kota Bengkulu dilihat dari hasil kuesioner atlit memiliki $82,7 \%$ dalam kategori sangat baik, pelatih memperoleh presentase $89,9 \%$ dalam kategori sangat baik sedangkan pengurus dojang memperoleh presentase 90,2\% dalam kategoris angat baik dan maka dari itu hasil keseluruhan skor 157,8 persentase $(87,62 \%)$ dengan kriteria sangat baik. Hasil ini membuktikan bahwa Studi Prestasi Atlit Taekwondo Pada Nomor Kyorugi dan Pada Nomor Poomse Di Kota Bengkulu masih dalam kategori Sangat baik. 


\section{A. Saran}

Berdasarkan kesimpulan, saran yang dapat disampaikan yaitu

1. Kepada atlit yang hasil kuesioner masuk kategori baik untuk terus berusaha dan giat berlatih agar nantinya semkain membuka asa bengkulu berprestasi di tarap nasional dan internasional

2. Kepada pengurus club/ dojang terus berusaha mengembangkan potensi atlit dan berinovasi dalam mengembangkan potensi atlit.

3. Kepada pelatih terus berusaha mengembangkan bakat atlit agar di masa depan olahraga Taekwondo bisa menjadi salah satu olahraga unggulan di Provinsi Bengkulu.

\section{DAFTAR PUSTAKA}

Ariansyah, A., Insanistyo, B., \& Sugiyanto, S. (2017). Hubungan Keseimbangan Dan Power Otot Tungkai Terhadap Kemampuan Tendangan Dolly Chagi Pada Atlet Ukm (Unit Kegiatan Mahasiswa) Taekwondo Universitas Bengkulu. Kinestetik: Jurnal Ilmiah Pendidikan Jasmani, 1(2), 111-116.

Arikunto, Suharsimi. (2003). DasarDasar Evaluasi Pendidikan. Jakarta: Bumi Aksara.

Bridge, C. A., da Silva Santos, J. F., Chaabene, H., Pieter, W., \& Franchini, E. (2014). Physical and physiological profiles of taekwondo athletes. Sports Medicine, 44(6), 713-733.

Cahyani, F. D. (2015). Pengaruh Latihan Menggunakan Pembarat Kaki Terahadap Kemampuan
Tendangan Dollyo Chagi Atlet Taekwondo putra kabupaten Dharmasyah. 1-2

Hidayat, C., \& Juniar, D. T. (2017). Penerapan Model Cooperative Learning Tipe Jigsaw terhadap Hasil Belajar Keterampilan Poomsae I Mata Kuliah Taekwondo. Jurnal Pendidikan Jasmani dan Olahraga, 2(2), 3642.INDONESIA, P. B. (2014). Diklat dan Penyelenggaran Penguji Nasional . bogor: PBTI.

Kazemi, M., Waalen, J., Morgan, C., \& White, A. R. (2006). A profile of Olympic taekwondo competitors. Journal of sports science \& medicine, 5(CSSI), 114.

Maiyanti,Sri Indra1. (Januari 2012). Analisis Prestasi Atlet Olah Raga Taekwondo Menggunakan Analisis Jalur (Studi Kasus Atlet Taekwondo-In di Karigamas Sport Club-Palembang). Volume 15 Nomer 1(A) 15102, 6-10.

Marković, G., Mišigoj-Duraković, M., \& Trninić, S. (2005). Fitness profile of elite Croatian female taekwondo athletes. Collegium antropologicum, 29(1), 93-99.

Matsushigue, K. A., Hartmann, K., \& Franchini, E. (2009). Taekwondo: Physiological responses and match analysis. The Journal of Strength \& Conditioning Research, 23(4), 1112-1117.

Pieter, F., \& Pieter, W. (1995). Speed and force in selected 
taekwondo techniques.

Biology of sport, 12, 257-266.

Pujianto, dian. (2018). Manajemen pendidikan dan olahraga . In $\mathrm{m}$. Dr. Dian pujianto, manajemen pendidikan dan olahraga (p. 49). Bengkulu: fakultas keguruan dan ilmu pendidikan universitas bengkulu.

Pujianto, Dian . (2018). manajemen pendididikan olahraga ., manajemen pendidikan olahraga (p. 49). BENGKULU : Fakultas Keguruan dan Ilmu Pendidikan Universitas Bengkulu

Southwick, R. (2004). Taekwondo Poomse, Taeguk, Palgwe. Micigan State University: 2004.08.30 12:46:21 - 04'00'.

Sugiyono, P. D. (2011). Metode penelitian kuantitaif, kualitatif dan $r \& d$. Bandung: alfabeta, cv.

Sobur, Alex. (2003). Psikologi Umum. Bandung: CV Pustaka Setia

Sudijono, Anas. (2009). Pengantar Statistik Pendidikan. Jakarta: PT RajaGrafindo Persada.
Taylor, M. W. (2009). Tucker Taekwondo Center. 1-23.

Zhaifa Kharisia Equata, M. Y. (2010). Hbungan antara Persepsi Atlet Teakwondo Junior pada Program Latihan dengan Motivasi. HUBUNGAN ANTARA PRESEPSI ATLET TAEKWONDO, 1-10. 